\title{
Impacting the COVID-19 Pandemic by Inducing Temporary Non-Specific Immunity
}

\author{
kamiar Alaei ${ }^{1}$ and Atena Farkhondeh ${ }^{2}$ \\ ${ }^{1}$ CSULB \\ ${ }^{2} \mathrm{NIH}$
}

August 22, 2020

\begin{abstract}
Following respiratory viral infections, there is a brief window in which a host has less susceptibility to other respiratory viruses. This is essential, as it may take up to 1 year to develop a vaccine. Most people get SARS-CoV-2 from their infected relatives at home, particularly during the first two weeks after exposure. Self-quarantine does not necessarily reduce the level of exposure for the relatives interacting with infected patients. The new infection may happen at least 10-14 days after the first infection. We propose to induce other viral respiratory infections such as non-fatal, mild, and self-limited Rhinoviruses or Coronavirus, which cause the common cold, prior to exposure to COVID-19. This would be beneficial for surrounding community members of infected individuals. In conclusion, theoretically we may protect immediate relatives of an infected person for at least two weeks, during active screening, by inducing temporary-immunity through the administration of non-fatal respiratory viruses.
\end{abstract}

\section{Hosted file}

$1000 \mathrm{~W}$ Impacting the COVID-19 Pandemic.docx available at https://authorea.com/users/351910/ articles/476330-impacting-the-covid-19-pandemic-by-inducing-temporary-non-specificimmunity 